\title{
Removing artificial variability from a physiotherapy service helps to reduce length of stay in an orthopaedic enhanced recovery pathway.
}

Tom Wainwright and Robert Middleton Orthopaedic Department, The Royal Bournemouth Hospital, and the Centre of Postgraduate Medical Research and Education, Bournemouth University.

International Forum on Quality and Safety in Health Care, 5-8 April 20II, Amsterdam.

\section{Context}

This work was completed in the orthopaedic department of a district general hospital in the United Kingdom The project involved patients having a hip or knee replacement operation. It was identified that patients who had operations on different days of the week experienced different standards of rehabilitation after their operation. There was unacceptable variation in patient experience and quality of care provided.

\section{Assessment of problem}

Analysis was completed using Dr Foster software. This illustrated differences to length of hospital stay depending on the day of operation. The analysis used case-mix adjustment methodology to control for natural differences in demographics. Staff then completed a root cause analysis to ascertain why this was happening.

\section{Intervention}

The physiotherapy service was changed to remove artificial variation in the provision of rehabilitation to patients who had operations on a different day. A business case was made and supported to change the physiotherapy service from a 5-day Monday to Friday service, to a 7-day a week service with extended working hours until 8pm from Monday to Friday. Standardised operating procedures were also introduced so that each patient received the same physiotherapy program and timings of physiotherapy interventions were recorded

\section{Lessons learnt}

Effective pathways need to be supported by organisational structures and staffing arrangements which allow them to work. Pathways usually centre of clinical processes, but we have learnt that these must be accompanied by managerial changes in order to allow the clinical changes to be performed for every patient.

\section{Key Message}

High quality patient pathways should remove all possible sources of artificial variation. We have illustrated the improvement to quality possible by removing the variability in our physiotherapy service provision.

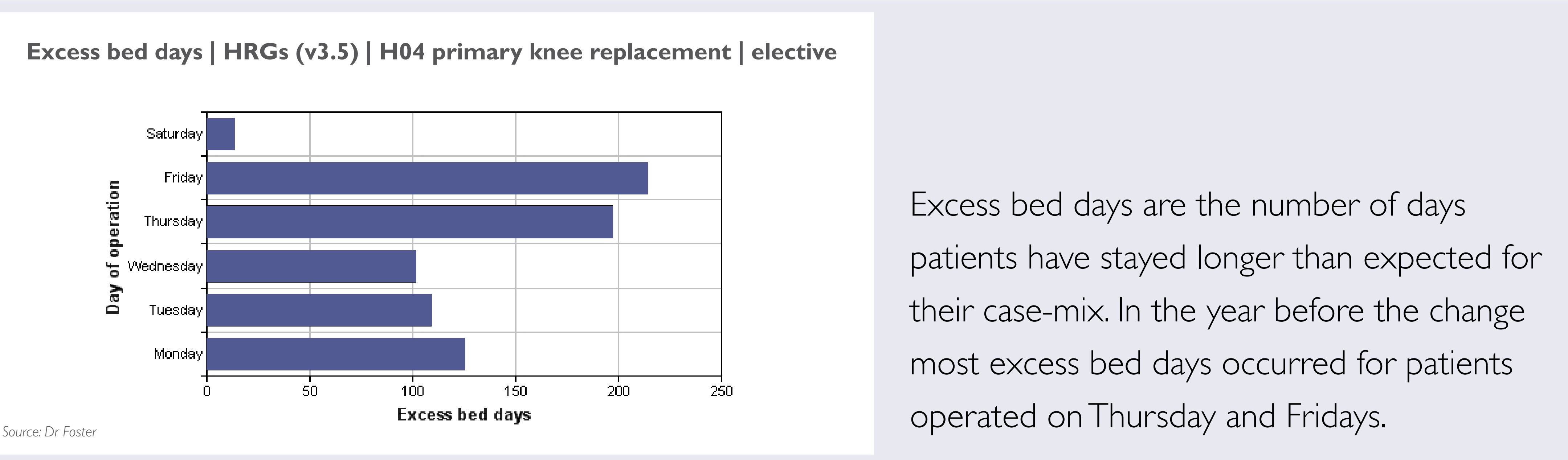

Excess bed days | HRGs (v3.5) | H04 primary knee replacement | elective

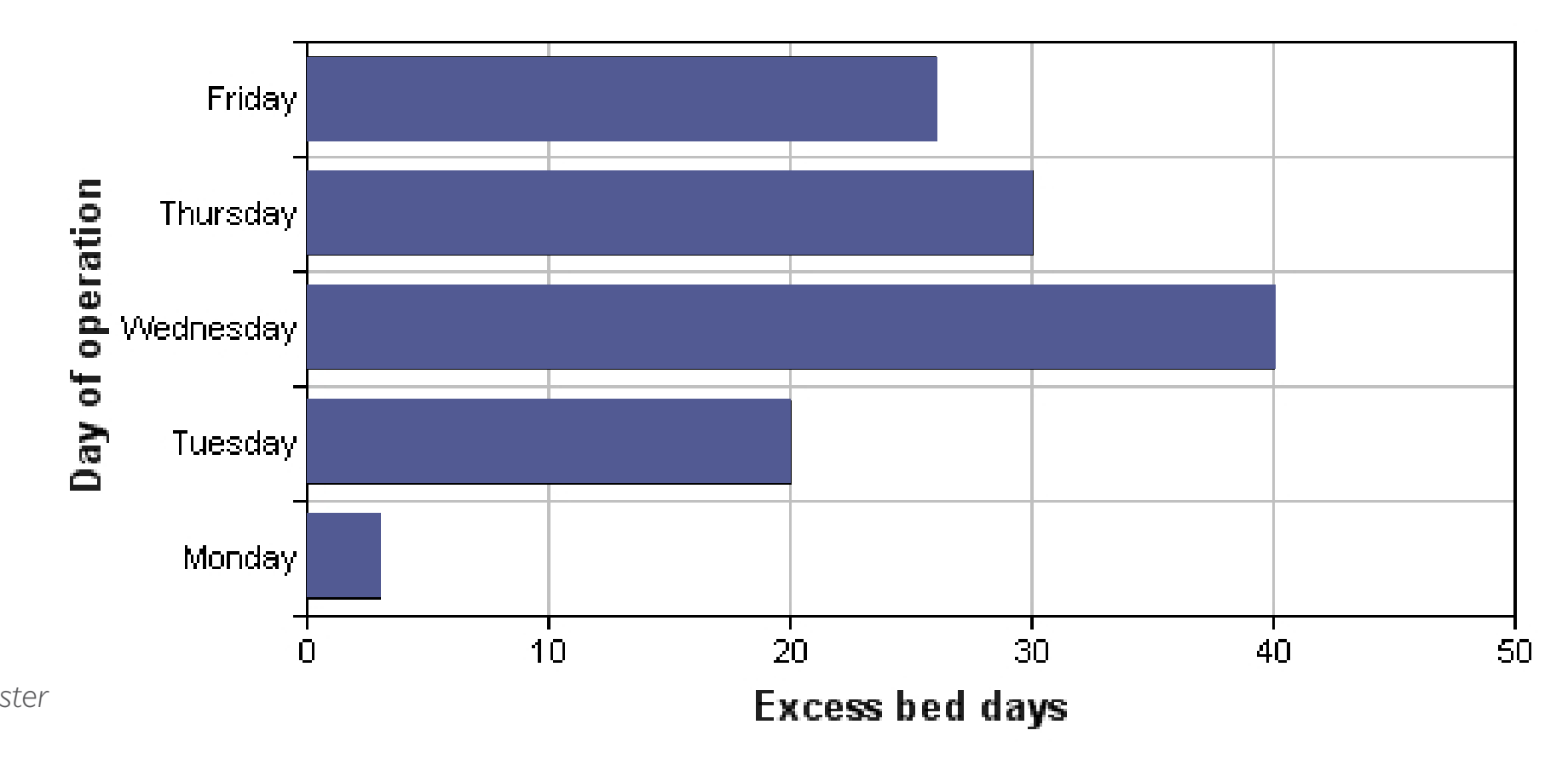

The graph on the right shows the dramatic reduction in excess beds days across all days of the week.

Spells | HRGs (v3.5) | H04 primary knee replacement | elective

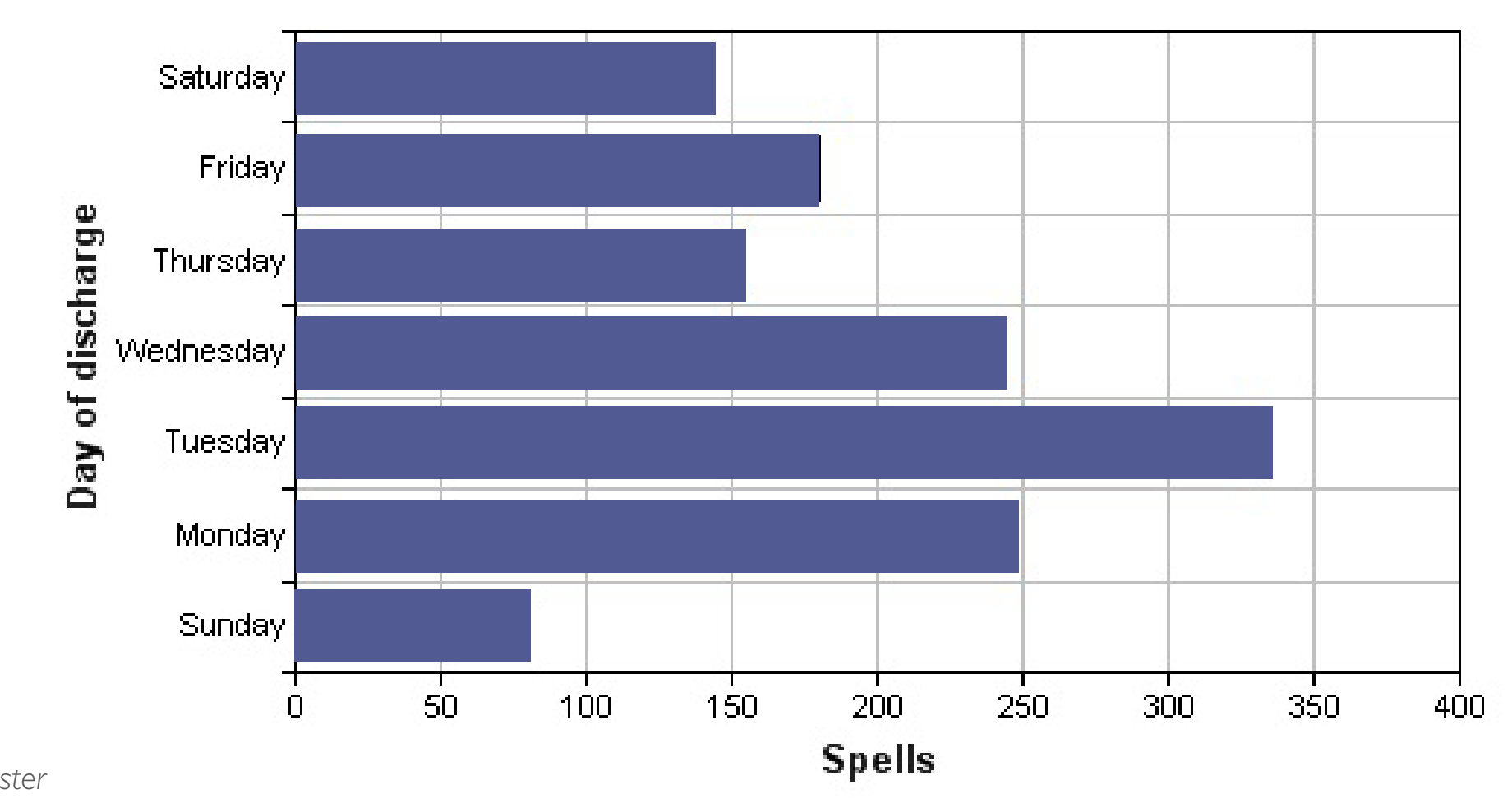

Before the change there were fewest discharges at the weekend and so consequently there was a backlog of patients to receive physiotherapy on a Monday and Tuesday.
Excess bed days | HRGs (v3.5) | H04 primary knee replacement | elective

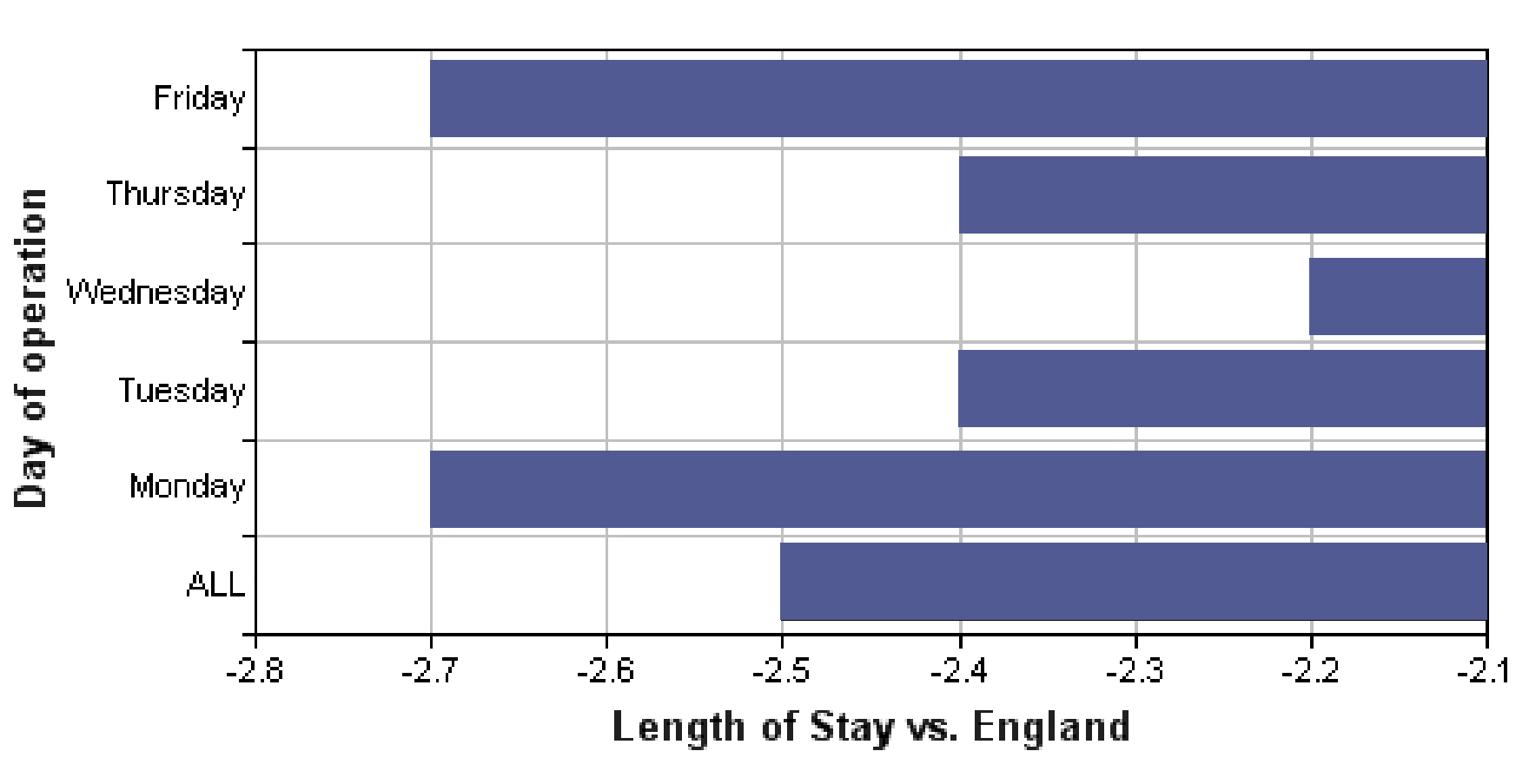

After the change the graph on the right shows the high number of weekend discharges following the introduction of a 7 day physiotherapy service. 